\title{
Broadening your library's collection Implementing a LGBTQIA collection development project
}

A constant concern for libraries is providing a collection of resources that are relevant to its patron population. Since most libraries have budgetary concerns that must be weighed against these needs, sometimes certain collection areas go underdeveloped. This is by no means the fault of the librarians, but priorities must be set and things fall behind. However, in many cases, it takes a reminder of patron needs to bring to light holes in a library's collection. This is what transpired to me at Jackson Library at Lander University.

\section{The project is born}

In August 2016, the Jackson Library director asked me if we had access to the magazines Out and The Advocate. This was not an uncommon request, given that I was often asked to check access to resources. Once I told her that we only had digital access to The Advocate and no access to Out, I thought that would be that. I was concerned about the lack of access to these resources, but I was not in charge of purchasing resources like these, so I put it out of my mind. However, later that afternoon, the director asked me to start a project to assess our lesbian, gay, bisexual, transgender, queer, intersex, and asexual (LGBTQIA) resources. She was curious about the state of our resources in that area, since subjects pertaining to LGBTQIA concerns span different collection development areas, and it had not been anyone's job to keep up with these topics.
I could not have been happier about this project. I was still new to my position, having only been working as a full-time librarian since the beginning of July. I knew that this was a great and important opportunity for me, especially so early in my career. Not only was this a great professional development project for me, it also excited me because I am an avid advocate of LGBTQIA rights and scholarship. I was excited to be able to assess the collection at our library for these resources. Despite this initial excitement, what I found was disconcerting, which led to a much larger task than I originally expected.

\section{Assessing our collection}

From the outset, I knew that searching the collection would be a multifaceted process. Not only did I want to assess the lesbian, gay, bisexual, and transgender (LGBT) resources in our library, but I also wanted to include the entire community in my research. To this end, I also wanted to assess the queer, intersex, and asexual (QIA) resources in our collection, as well as any other resource pertaining to the community as a whole. In addition to finding books that covered these topics, I also needed to look in many different subject areas. Since

Rebekah Scoggins is teaching and learning librarian at Lander University's Jackson Library, email: rscoggins@ lander.edu

(C) 2018 Rebekah Scoggins 
I wanted to search so many different topics and areas, I knew there was not one singular keyword, subject heading, or search string that I could use to find all the LGBTQIA books we had in our collection. This meant I had to try many different searches and amalgamate those results into cohesive statistics.

This process took some time. I started with a straight forward keyword search in the online catalog, then opened it up to variations on the words using truncation and different forms of the words. These words included homosexual, homosexuality, lesbian, gay, bisexual, bisexuality, transgender, intersex, queer, asexual, asexuality, and sexuality. I then followed a series of subject headings

\section{that were \\ used on the books I found in our collec- tion, such as gay and les- bian stud- ies, sexual} orientation, homosexuality, and various others. I then spent some time walking through our stacks,

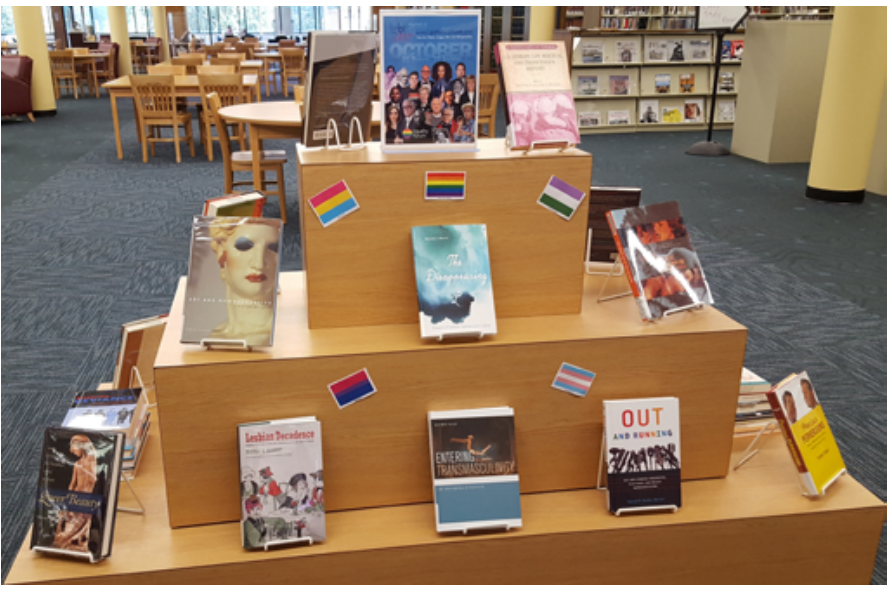

The full LGBT History Month display, highlighting the official LGBT History Month poster, many of the books from the collection development project, and the different flags that represent the subsets within the LGBTQIA movement. and society, our collection was also limited in its scope. There were no titles dealing with asexuality or intersex individuals and only a slim amount of books addressing transgender individuals and bisexuality.

\section{Filling the gaps}

From this point, I knew I wanted to attack these gaps in our collection head on. To find out how to proceed, I went to the library director and told her about my findings. When I explained the vast holes in our collection, she told me to start looking for books that would help fill this gap. I knew this was going to be another significant process, considering how many keywords and search strings I had to use just to assess our looking in

the areas where books on these topics were generally cataloged. This includes many of the HQs, ranging mostly from HQ20 to HQ80, and some in other subject areas around the library, depending on the slant of the book.

After the completion of my search, I discovered that our collection was severely lacking in this area, both in number and up-to-date resources. Based on the publication dates of our collection, only very limited collection development had been done in this area during the past seven years. Aside from a smattering of titles dealing with LGBTQIA literature, history, collection. Plus, there have been so many changes in the sexuality rights movement, legislature, and scholarship in the past six or seven years, so I knew there was a lot of ground to cover.

To start the next part of my project, I did extensive research into current print books that deal with the most important societal issues in this sector. I also wanted to buy more books that dealt with LGBTQIA resources in different disciplines, such as art, literature, history, and film. This search took me to the conventional places I use for collection development, such as our vendor catalog, topical book catalogs, and online book retailers, such as Amazon. However, I also wanted to make sure I was getting high-quality resources that were relevant in the field and for the LGBTQIA community at large. 
This led me to look through other university catalogs, book reviews from official organizations, as well as readers, blogs from LGBTQIA community members, and any other place that I could find information about titles in this subject area.

$A$ t $\mathrm{e} r$

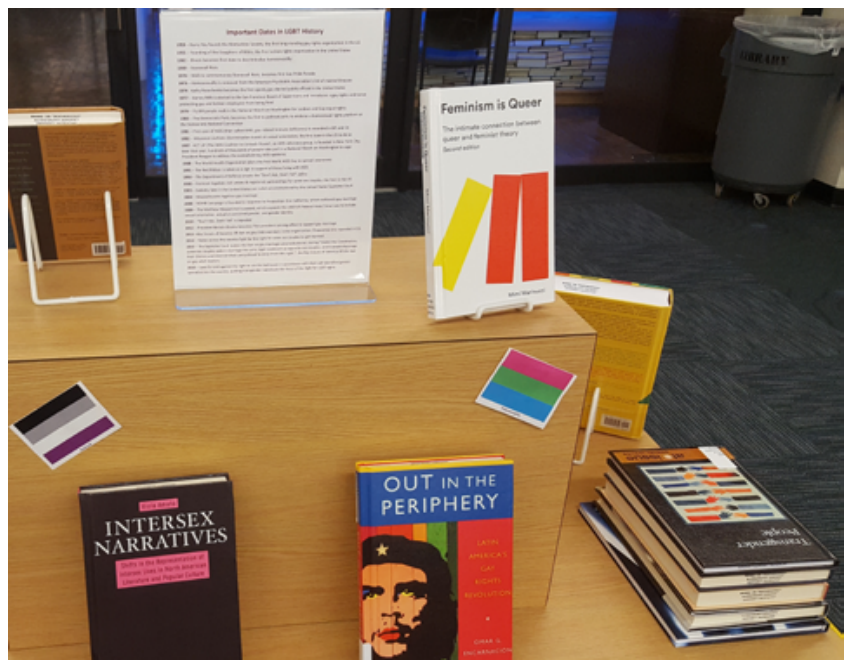

Once the books arrived, I knew I wanted to showcase this new collection to our students, faculty, staff, and community members. With our new books, I developed multiple book displays highlighting our collec-

Detail of the LGBT History Month display, showing a display tion, which poster that highlighted important dates in LGBT history, as well were each left as some of the books bought for the collection development up for many project.

successive weeks in our weeks of searching and making wish lists of the resources I wanted to buy for the library, I took my list back to the director. The list was much larger than what I could buy in one month for a particular department or on the same subject matter, so I expected to have to purchase titles over time. However, I was allowed to use funds from a discretionary collection development fund to buy a large portion of resources to get the project started. From my initial wish list, I selected almost $\$ 1,700$ in new materi-
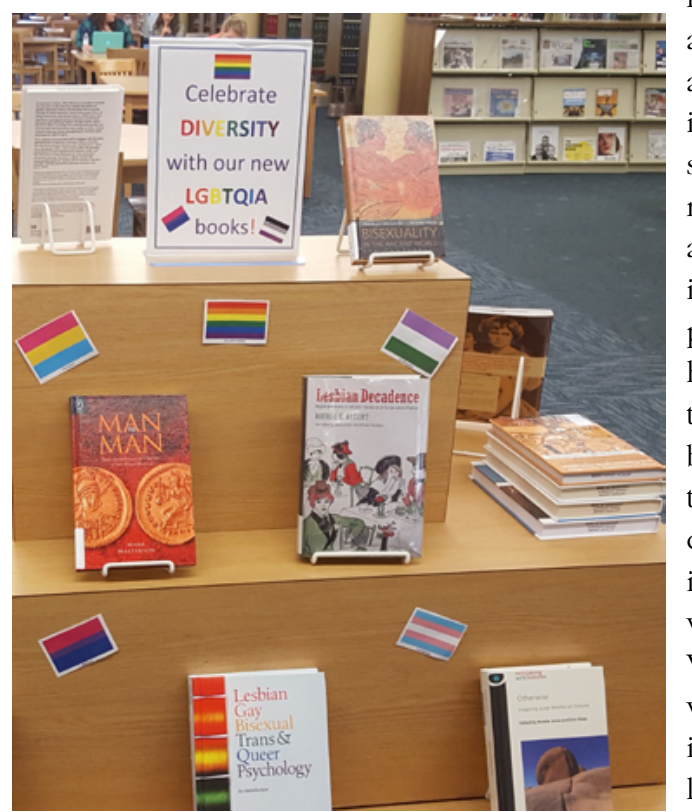

A second LGBTQIA display, highlighting additional materials that came in from the collection development project.

als to enrich our library's LGBTQIA resources. ${ }^{1}$ After this initial push, LGBTQIA resources would then be a part of my normal monthly collection development.

(continues on page 126) 


\section{Conclusion}

While we do not have the power to dictate how a space is viewed, we can "set a tone and invite people in" by providing interesting topics and interactive displays. ${ }^{2}$ Doing so allows everyone the opportunity to cocreate the library's space and culture in a way that values and generates self-expression. Students especially have what TESOL scholars refer to as a willingness to communicate, or a readiness to volunteer ideas and opinions with others. What they need are chances to do so in an environment where they can feel comfortable and confident in their contribution being valued and free from judg- ment. ${ }^{3}$ Interactive displays in the library are one way of offering and developing that environment together.

\section{Notes}

1. Brian Mathews and Leigh Ann Soistmann, Encoding Space: Shaping Learning Environments that Unlock Human Potential (Chicago: ACRL, 2016) 24.

2. Ibid., 101.

3. P. D. MacIntyre, Z. Dörnyei, R. Clément, and K. A. Noels, "Conceptualizing Willingness to Communicate in a L2: A Situational Model of L2 Confidence and Affiliation," The Modern Language Journal 82, no. 4 (1998): 545-62. $\approx 2$

("Broadening your library's collection," continues from page 116)

\section{Larger implications}

The magnitude of this collection development project reaches beyond the general importance of normal library collection development because of the university community that I serve. Lander is a small, regional Southern stateassisted, four-year university in a very rural area. In these kinds of remote, Southern areas that are typically steeped in religion, bringing access to current and unbiased information about sexuality, LGBTQIA history, and the LGBTQIA rights movement is extremely important. The point of higher education is to enrich and broaden the minds of our students and community, and I believe that making this topic visible and available is just the beginning of getting this topic out there and accepted. Also, since we as an institution are responsible for the information and research needs of our students, this collection development project was instrumental and necessary for our community. It was also necessary to pinpoint and resolve such a glaring gap in our resources.

\section{Implementing this in your library}

There are many of you who may want to tackle this kind of targeted collection development project. I was very lucky to have a wonderful and understanding director who allowed me free range on this subject, as well as fiscal assistance for the project. For your library, I suggest starting with the idea. Look in your collection for an area that you think has, for one reason or other, been overlooked. You may already have a topic that you can work with or you may want to increase your LGBTQIA resources like I did. No matter what your topic, the first step is to research what books are needed in this subject area. Hunt down the best resources that cover this topic, and make a wish list.

Some of you may not be able to make a large purchase like I was, but that doesn't mean you cannot make a difference. Try to order as many books as you can at any point in your purchasing process. Even if it is a few books a month, over time, you will be able to fill any holes in your collection. And don't be afraid to tackle difficult topics or subject areas. These are the areas where people learn, grow, and are challenged by ideas outside their comfort zones. Through these kinds of initiatives, you can, little by little, make a difference, not only in your collection, but for your university as a whole.

\section{Note}

1. To see the full list of the books we bought for Jackson Library, visit http://bit. ly/2z1oJwA. $\neq 2$ 